\title{
OBJEK AMATAN PADA TIPO-MORFOLOGI RUANG PONDOK PESANTREN SALAF-TRADISIONAL
}

\author{
Ririn Dwi Lestari \\ Mahasiswa Program Magister Jurusan Arsitektur Lingkungan Binaan Fakultas Teknik Universitas \\ Brawijaya Malang : ispep: \\ e-mail : ririnlestari90@gmail.com \\ Antariksa \\ Dosen Program Magister Jurusan Arsitektur Lingkungan Binaan Fakultas Teknik Universitas \\ Brawijaya Malang is:pep: \\ e-mail : antariksa@ub.ac.id \\ Jenny Ernawati \\ Dosen Program Magister Jurusan Arsitektur Lingkungan Binaan Fakultas Teknik Universitas \\ Brawijaya Malang is:ep: \\ e-mail : jenny_ernawati@ub.ac.id
}

\begin{abstract}
ABSTRAK :
Pondok Pesantren Salaf-Tradisional merupakan model sistem sosial sekaligus sistem intelektual yang pertama dan tertua di Indonesia. Sebutan di Jawa, Sunda dan Madura adalah Pesantren atau Pondok, di Minangkabau Surau (Dayah), di Aceh dinamakan Rangkang (Meunasah).

Lembaga ini bertujuan untuk memahami, menghayati dan mengamalkan ajaran Islam dengan menekankan pentingnya moral agama sebagai pedoman hidup bermasyarakat sehari-hari. Melalui pengkajian kitab klasik atau kitab kuning, dengan metode sorogan, bandongan atau wetonan, dan hafalan serta halaqoh. Tujuan penulisan ini untuk mengetahui objek amatan apa saja yang dapat menjadi panduan untuk mengamati tipo-morfologi tipe 'ibu' atau tipe dasar/tradisional penyelenggaraan ruang-ruangnya.

Melalui elaborasi teori ruang dan sintesa objek amatan dari penelitian terdahulu yang terkait, diperoleh objek amatan pada Ruang Luar berupa, (1)Organisasi Massa, (2)Lay-Out dan (3)Tatanan Massa dengan variabel amatan (a)Bentuk Massa, (b)Konfigurasi Massa, (c)Orientasi Massa, (d)Pola Sirkulasi, (e)Hirarki Massa dan (f)Transformasi Massa. Objek Amatan pada Ruang Dalam yaitu, (1)Organisasi Ruang, (2)Denah Ruang, (3)Teritori Ruang dan (4)Tatanan Ruang dengan variabel amatan (a)Bentuk Ruang, (b)Konfigurasi Ruang, (c)Orientasi Ruang, (d)Sirkulasi Ruang, (e)Elemen Pembatas Ruang, (f)Teritori Pemanfaatan Ruang, (g)Hirarki Ruang dan (h)Transformasi Ruang.

Tanpa mengetahui tipe dasarnya, tidak mungkin bisa mengenal peran pentignnya dalam sejarah perjuangan bangsa hingga sekarang, apalagi mampu melestarikan nilai-nilai tradisi/kultur luhur yang dimilikinya.
\end{abstract}

Kata kunci : pesantren, tipo-morfologi ruang, objek amatan

\section{ABSTRACT :}

Pondok Pesantren Salaf-Tradisional is the first and oldest model of social system and intellectual system in Indonesia. The name in Java, Sunda and 
Madura is Pesantren or Pondok, in Minangkabau Surau (Dayah), in Aceh called Rangkang (Meunasah).

This institute aims to understand, live and practice the teachings of Islam by emphasizing the importance of religious morals as a guide of daily life. Through the study of the classic book or yellow book, with the method of sorogan, bandongan or wetonan, and memorization and halaqoh.

The purpose of this paper is to know what objects of observation can be a guide to observe the type of 'mother' typology or the basic type of the organization of the spaces.

Through the elaboration of space theory and the synthesis of observational objects from previous related research, the observed objects in the Outer Space are: (1) Mass Organization, (2) Lay-Out and (3) Mass Order with observed variables (a) Mass Form, b) Mass Configuration, (c) Mass Orientation, (d) Circulation Pattern, (e) Mass Hierarchy and (f) Mass Transformation. The observed objects in the Inner Space are: (1) Space Organization, (2) Space Lay-Out, (3) Space Teritory and (4) Space Layout with observed variables (a) Form, (b) Configuration, (c) Spatial Orientation, (d) Circulation, (e) Space Limiting Elements, (f) Territory, (g) Hierarchy and (h) Transformation.

Without knowing the basic type, it is impossible to recognize the important role in the history of the nation's struggle up to now, let alone be able to preserve the values of tradition / noble culture it has.

Keywords: pesantren, tipo-morphology of space, observation object

\section{PENDAHULUAN}

Perjalanan sejarah Nusantara telah mencatat bahwa sejak masa pra kolonial, kolonial dan pasca kolonial hingga masa sekarang ini, peran dan kontribusi pesantren dalam bidang sosial, politik, budaya dan hankam sangat besar. Pondok pesantren adalah model sistem sosial sekaligus sebagai sistem intelektual yang pertama dan tertua di Indonesia, yang mampu bertahan hingga saat ini (Anwar, A. dalam Ibrahim, R., 2014).

Kemampuannya bertahan hingga masa modern saat ini menurut banyak peneliti dalam Ibrahim (2014) dikarenakan :

a. Kultur Jawa yang involutif dan menekankan harmoni, sehingga mampu menyerap kebudayaan luar tanpa kehilangan identitasnya (Azyumardi Azra);

b. Figur Kyai yang menonjol dengan ilmu dan visinya (Hasan Langgulung, $\mathrm{H})$;

c. Pola kehidupannya yang unik sebagai sub kultur Abdurrahman Wahid);

d. Telah berhasil mengantar santrinya untuk menguasai kitab kuning sebagai ilmunya ulama salaf yang dipercayai kebenarannya (Ali Anwar);

e. Budaya pesantren sebagai "great tradition" dalam pengajaran agama, yaitu mentransmisikan Islam tradisional dalam kitab kuning (Martin van Bruinessen). 
Perkembangan peradaban dunia saat ini (globalisasi) yang bersumber dari barat begitu kuat, terutama di bidang ekonomi, ilmu pengetahuan dan teknologi. Globalisasi mempengaruhi segenap aspek kehidupan, baik di bidang ideologi, politik, sosial, budaya, ekonomi dan hukum (Nata, A., 2012). Semua itu dapat mengubah gaya hidup dan tata nilai yang berlaku di masyarakat secara universal. Hal-hal yang sebelumnya bersifat tabu atau terlarang dalam agama Islam, bisa jadi bertentangan dengan tata nilai peradaban Barat.

Tak dapat dipungkiri lagi bahwasanya hegemoni Barat di era globalisasi ini ditopang oleh nilai-nilai hedonis-materialistik, sekularisme, pluralisme yang mewarnai bahkan merusak tata nilai Islami yang telah melekat pada diri bangsa sejak masuknya Islam abad $7 \mathrm{M}$. dan berkembangnya pesantren sejak abad 14 M. (Rofi', 2016).

Kondisi ini mengakibatkan degradasi moral di kalangan generasi muda bangsa Indonesia, terutama di wilayah perkotaan. Dengan sistem pendidikan modern yang dibawanya, seolah seperti pedang bermata dua. Di satu sisi telah membawa kemajuan yang bersifat positif, menghasilkan manusia-manusia yang cerdas dan tanggap teknologi, sementara di sisi lain, keteguhan memegang prinsip kejujuran, keadilan dan kebenaran semakin goyah, bahkan tidak memiliki akhlak mulia dan terjerumus ke dalam kehidupan yang merusak sebab tidak memiliki benteng pemahaman agama yang memadai dari pendidikannya.

Dampak buruk pada segala lapisan masyarakat termasuk pada jajaran kepemimpinan adalah dekadensi moral. Terbukti dengan banyaknya kasuskasus asusila dan korupsi terutama di kalangan pemimpin negara. Hal ini menunjukkan aspek kehidupan dan politik bangsa perlu segera dilakukan perbaikan.

Nilai-nilai di dalam tradisi pesantren yang mempunyai tujuan utama mempelajari dan mendalami ilmu agama melalui kitab-kitab Islam klasik, sekaligus juga menanamkan pembiasaan hidup yang sederhana, disiplin, jujur dan mandiri, serta pemahaman yang baik terhadap ajaran agama Islam diharapkan mampu memperkuat akhlak dan moral serta prinsip-prinsip kebenaran dan keadilan yang hakiki sehingga mampu menjaga, bertahan dan menolak pengaruh-pengaruh buruk tersebut.

Tradisi yang dimiliki pesantren tipe awal ini, eksis sampai sekarang, karena caranya beradaptasi terhadap perkembangan dan perubahan jaman. Tradisi khas ini tidak dimiliki oleh lembaga pendidikan lainnya serta tidak ditemukan di negara lain, bahkan di Timur Tengah tempat asal agama Islam.

Pondok Pesantren Salaf-tradisional dijadikan objek kajian karena dapat mewakili type 'ibu' atau tipe dasar/tradisional pondok pesantren yang lahir di Indonesia, yang telah berjasa besar bagi perjuangan bangsa dan memiliki nilainilai moral yang kuat untuk memperbaiki dan mempertahankan karakter moral bangsa terhadap nilai-nilai globalisasi yang tidak sesuai.

Nilai-nilai tradisi pesantren ini pada hakekatnya penyebab terciptanya 'produk' ruang. Melalui penciptaan dan pemaknaan ruang akan dapat 
mengenali dan memahami lebih mendalam nilai-nilai di dalam tradisi pesantren Salaf-tradisional. Tanpa mengenal dan mengetahui lebih mendalam, penyebab timbulnya 'produk' berupa ruang-ruang secara arsitektural ini tidaklah mungkin dapat melestarikan dan menjaga nilai-nilai tersebut dengan baik.

\section{TINJAUAN PUSTAKA}

\subsection{Pesantren Salaf-Tradisional}

Pondok Pesantren Salaf atau Salafiyah atau Tradisional (Pondok Pesantren Salaf-Tradisional), merupakan jenis Pondok Pesantren yang tetap mempertahankan kitab-kitab klasik sebagai inti pendidikannya, serta mengapresiasi budaya setempat atau melestarikan warisan tradisi dan ajaran ulama terdahulu serta tradisi lokal yang sudah melalui proses penyeleksian dengan standar ajaran para ulama terdahulu (normatifitas agama). Tradisi masa lalu sangat dipertahankan. Melalui sistem pembelajaran yang khas, yaitu dengan metode sorogan dan bandongan atau wetonan, hafalan dan halaqoh sedangkan sistem madrasah digunakan hanya untuk memudahkan sistem sorogan (Dhofier, 2011).

Secara fisik visual arsitektural bangunan pondok pesantren ini didirikan secara sederhana menggunakan 'bahasa' setempat atau bersimbol kerakyatan daerah lokal berdasarkan fungsi, kebutuhan dasar akan ruang yang secara subjektif dihadirkan oleh pemiliknya, yaitu seorang Kyai, sebagai fasilitas tempat atau wadah agar transfer ilmu keislaman kepada murid atau santri dapat berlangsung dengan baik. Kyai merupakan "arsitek" yang memprakarsai berdirinya pesantren ini.

Dalam sistem religi Islam pemaknaan wujud dan bentuk fisik bangunan bukan menjadi prioritas utama yang dapat mencerminkan substansi sebuah Pondok Pesantren Salaf-tradisional, sebab hal yang terpenting adalah kualitas spiritualitas yang dimiliki pendirinya.

Mukti Ali (1987) mengidentifikasi karakteristik (aspek non fisik) yang menjadi ciri khas pesantren Salaf-tradisional :

1) Adanya hubungan yang akrab antara santri dan kyai;

2) Tunduknya santri pada kyai;

3) Hidup hemat dan sederhana benar-benar dilakukan di pesantren;

4) Semangat menolong diri sendiri amat terasa dan kentara di kalangan santri di pesantren;

5) Jiwa tolong menolong dan suasana persaudaraan sangat ditekankan dalam kehidupan pesantren;

6) Kehidupan berdisiplin sangat ditekankan dalam kehidupan pesantren;

7) Berani menderita untuk mencapai suatu tujuan adalah salah satu pendidikan yang diperoleh santri di pesantren; dan

8) Kehidupan agama yang baik diperoleh santri di pesantren.

Elemen dasar sebagai aspek fisik dalam Pondok Pesantren Salaftradisional ada 5 elemen (Dhofier, 2011), yaitu :

a) Pondok; 
b) Masjid;

c) Santri;

d) Kyai; dan

e) Pengajaran kitab-kitab kuning.

Karakteristik di atas dapat disederhanakan dalam gambar 1 di bawah ini.

ASPEK NON FISIK (Ali, 1987) :

AKRAB (seperti Anak

dengan Orang Tua) ANTARA

SANTRI DAN KYAI;

TUNDUKNYA SANTRI PADA

KYAl;

HIDUP HEMAT DAN

SEDERHANA;

SEMANGAT MENOLONG;

SUASANA PERSAUDARAAN;

DISIPLIN;

BERANI MENDERITA UNTUK

MENCAPAI SUATU TUJUAN

KEHIDUPAN AGAMA YANG

BAIK.
ASPEK FISIK (Dhofier, 2011) :

KYAI

SANTRI

MASJID

PONDOK

PENGAJARAN KITAB

KUNING (Metode Sorogan,

Bandongan atau Wetonan,

Hafalan dan Halaqoh)
RUANG-RUANG

(Ruang Dalam dan

Ruang Luar)

\section{Gambar. 1}

Karakteristik Pesantren (Aspek Non Fisik dan Fisik) menghasilkan Ruang Sumber: RD. Lestari

\subsection{Ruang}

Ruang merupakan unsur paling esensial dalam Arsitektur (Zevi, 1957). Dengan mengenal ruang dan objek amatan ruang, maka akan dapat digambarkan tipo-morfologi suatu objek arsitektur.

Karena pentingnya makna ruang di dalam arsitektur, bahkan segala aspek di dalam arsitektur sebenarnya berhubungan dengan penyelenggaraan dan penataan ruang atau ordering principles (Ching, 2008) untuk mewadahi segala aktifitas manusia.

Ruang dapat dikategorikan menjadi dua, yaitu ruang dalam dan ruang luar. Dari kategori tersebut masih bisa ditinjau lebih dalam lagi menjadi ruang-ruang positif, ruang-ruang negatif maupun ruang-ruang diantaranya (Aguspriyanti \& Pujiono, 2012). Ruang juga dapat mengalami perubahan atau transformasi di dalam perjalanan masa yang dilaluinya sejak saat didirikan hingga saat sekarang (Moneo, 1979), berupa penambahan, pengurangan maupun pergerakan (Habraken, 1982).

Paul Oliver (1997) menekankan bahwa arsitektur adalah bentuk yang dalam konteks hunian atau permukiman, tidak hanya ditujukan untuk menciptakan tempat tinggal, tetapi lebih ditujukan sebagai tanggapan terhadap kebutuhan khusus yang merupakan ekspresi dari budaya penghuninya berdasarkan pengalaman yang telah dialami selama hidupnya. Hunian didefinisikan sebagai artefak yang dibangun oleh penghuninya melalui konteks budaya dan cara tradisional yang terbatas dengan cara yang lebih spontan dibandingkan dengan bangunan tinggi yang dirancang dalam lingkungan 
profesional, 'the direct and unself-conscious translation into physical form .... ' (Rapoport, 1969: 2).

\section{a. Setting Ruang}

Pengertian setting fisik ruang yang berkaitan langsung dengan disiplin ilmu arsitektur adalah suatu area yang secara fisik dibatasi oleh tiga elemen pembatas yaitu lantai, dinding, dan langit-langit (Ashihara, 1983). Elemen pembatas ini tidak selalu bersifat nyata dan utuh, tetapi dapat bersifat parsial dan simbolik, dan elemen sirkulasi termasuk didalamnya.

Lang (1987: 119) mengidentifikasi adanya tiga tipe fundamental setting fisik ruang (layout patterns), meliputi :

a) Ruang yang dibentuk oleh unsur fixed-feature, dinding solid/ permanen, lantai permanen, jendela, dan elemen lain yang bersifat permanen dalam ruang, yang mencakup juga organisasi ruang, orientasi, ukuran, lokasi, hirarki, dan mempunyai isẹpimakna yang terlihat, atau mempunyai arti tertentu;

b) Ruang yang dibentuk oleh unsur semi-fixed feature, merupakan elemenelemen yang agak tetap dan bersifat semi permanen yakni ruang terbentuk atas tatanan perabot, tabir pembatas, serta pola taman, sehingga karakter ruang mudah berubah; dan

c) Ruang yang dibentuk oleh unsur non fixed-feature, merupakan elemen elemen yang bersifat tidak tetap (non permanen ) dan mudah berubah baik letak maupun posisinya.

Setting ruang juga dapat menjelaskan perletakan ruang berdasarkan kualifikasi (Ronald, 2005) :

a) Public Space;

b) Semi Public Space;

c) Semi Private Space; dan

d) Private Space.

\section{b. Setting dan Sistem Aktifitas}

Rapoport (1969) dan Kent (1990) menggarisbawahi betapa pentingnya dan menjadi suatu kebutuhan untuk mendefinisikan konsep aktifitas ke dalam variabel-variabel. Ada 6 (enam) variabel menurut mereka di dalam teorinya, yang merepresentasikan sistem aktifitas, yaitu

1) Sifat alami daripada aktifitas itu sendiri (what);

2) Pelaku aktifitas atau bukan pelaku aktifitas (who);

3) Tempat berlangsungnya aktifitas (where);

4) Kapan atau saat terjadinya aktifitas (when);

5) Kaitan dengan aktifitas lainnya (how-icluding or excluding whom);

6) Makna aktifitas (the meaning).

Keenam elemen tersebut melingkupi baik pada area ruang luar suatu objek maupun pada ruang-ruang dalamnya. 


\section{c. Teritori Ruang}

Teritori adalah batas wilayah nyata yang statis yang berfungsi sebagai pengontrol privasi dan dibentuk oleh perorangan atau kelompok untuk memberikan identitas personal serta untuk mengatur sistem sosial (Altman \& Chemers, 1989). Kontrol diartikan sebagai mekanisme pengaturan batas antara yang satu dengan yang lain melalui penandaan atau personalisasi. Digolongkan menjadi tiga, yaitu :

1. Teritori primer atau privat, yaitu tempat yang sangat pribadi sifatnya dan hanya boleh dimasuki oleh orang-orang tertentu yang sudah sangat akrab atau sudah mendapat ijin khusus;

2. Teritori sekunder atau semi publik, yaitu tempat-tempat yang dimiliki bersama oleh sejumlah orang yang sudah cukup saling kenal atau dimiliki oleh kelompok sosial atau kelompok kerja tertentu; dan

3. Teritori tersier atau publik, yaitu tempat-tempat terbuka untuk umum yang pada prinsipnya siapapun boleh memasukinya. identitas.

Esensi teritori ruang meliputi aspek keamanan, kontrol, personalisasi dan

\section{d. Sistem Spasial}

Sistem spasial merupakan aspek mendasar dan paling stabil karena terbentuk sesuai dengan pola tingkah laku manusia. Sistem spasial berkaitan dengan denah, organisasi ruang, orientasi ruang dan hirarki ruang (Habraken dalam Ciptadi, 2014).

Untuk mengetahui karakter ruang tersebut menurut Habraken dalam Zubaidi (2009) dapat melalui tiga cara, yaitu :

a. Stylistic System, berhubungan dengan tampilan bangunan misalnya bentuk bangunan;

b. Physical System, mengidentifikasi melalui karakteristik komponennya yaitu bahan dan struktur elemen pembentuk ruang;

c. Spatial System, mengidentifikasi karakter ruang dan bagaimana hubungan antara ruang-ruang tersebut orientasi maupun hirarkinya.

Sistem Ruang menurut Mannual Marti Jr. dalam Sholahuddin (2014) dapat digambarkan sebagai keterkaitan antara man, space dan time.

Organisasi Ruang merupakan struktur pengaturan ruang pada denah sebagai tempat melakukan aktifitas pribadi maupun komunal. Bentuk-bentuk organisasi ruang, yaitu terpusat, linier, radial, cluster dan grid (Ching, 2008).

Aspek ruang pada hunian menjelaskan beberapa hal menurut Ronald (2005), yaitu :
a) Arah (orientation);
b) Letak (setting);
c) Tingkatan (hierarchy);
d) Keterbukaan (transparancy); dan
e) Besaran Ruang (size). 


\section{e. Perubahan Ruang}

Perubahan ruang berkaitan langsung dengan tipo-morfologi ruang dari saat ruang-ruang terbentuk sampai kondisinya saat ini setelah melalui perjalanan masa.

Saverio Muratori dalam Moudon (1997) mendefinisikan tipo-morfologi sebagai sebuah alat untuk meneliti struktur spasial menjadi sebuah bentuk material yang konkrit yang mengandung fungsi dan kegunaan tertentu. Menurut Muratori, bentuk mewakili lebih dari sekedar dimensi dan fungsi, di dalamnya mencakup ide-ide dan pengalaman dari budaya lokal. Dengan mempelajari bentuk, juga harus mempelajari budaya yang menyertainya, jadi :

1. Bangunan dan lingkungan tidak dapat dipisahkan. Mereka harus dipertimbangkan bersama dalam analisis dan desain;

2. Bagian kota tidak dapat dianggap terpisah dari seluruh kota; dan

3. Kota hanya dapat dipahami dalam dimensi sejarah karena muncul dari suksesi reaksi dan proses pertumbuhan.

Tipo-morfologi diterapkan untuk memformulasikan 'archtipe' --'ibu' dari semua jenis (tipe) dan mencoba untuk merekonstruksi garis perkembangan dari pola dasar ini untuk jenis (tipe) yang berikutnya.

Muratori mendefinisikan 'tipe' sebagai sebuah konstruksi konvensi dan norma-norma yang ada di suatu wilayah atau kota tertentu dan yang berevolusi dari waktu ke waktu atas dasar pengalaman. Tipe merupakan pasangan dari standar, dimana tipe memiliki kekayaan makna dan budaya, sedangkan standar mengacu pada norma-norma teknis. dan sejarah bukan hadir hanya untuk memuaskan keingintahuan, tetapi harus berguna dan 'bekerja' dalam proses desain, seperti istilah Muratori, 'storia operante' (operative history).

\subsection{Penelitian Terdahulu yang Terkait}

Melalui beberapa penelitian terdahulu yang terkait, objek-objek amatan dalam kajian-kajian tersebut (menyangkut Sistem Spatial dan Tipo-Morfologi dalam skala kota atau kawasan) adalah sebagai berikut :

Tabel 1.

\section{Objek Amatan pada Penelitian Terdahulu yang Terkait}

No. Judul dan Tahun Objek-Objek Amatan

1. Identifikasi Pola Morfologi Kota (Studi Kasus : Secara Struktural, Fungsional dan Visual pada unsur : Sebagian Kecamatan Klojen, di kota Malang)-

Tallo, Amandus Jong et al

3. Tipe-tipe bangunan (place)

2. Pengaruh Perkembangan Perkotaan Terhadap Morfologi Kampung Kauman Kota Semarang2013
1. Penggunaan Lahan (land use)-Teori Figure Ground

2. Pola-pola Jalan-Teori Linkage

3. Tipe-tipe bangunan (place)

Alie, Cynthia Putriyani \& Suwandono, Djoko 
3. Morfologi Kampung Kalengan Kelurahan Bugangan Kota Semarang-2013

Fadhilah, Arief et al

1. Rekonstruksi morfologi kampung berdasarkan waktu

2. Elemen perkembangan ruang kampung :

- skema sirkulasi

- penggunaan lahan

- massa bangunan

3. Komponen fisik penyusun ruang :

- ruang halaman/lapangan

- ruang jalan

4. Komponen non fisik penyusun ruang :

- aspek sosial ekonomi

- aspek sosial budaya

1. Identifikasi Makro : - Land Use (Penggunaan Lahan) ; -

Building Structure (Tipe dan Massa Bangunan) ; -Plot Pattern

(Pola Kapling); -Street Pattern (Pola-pola Jalan/Sirkulasi

2. Identifikasi Mikro : -Berdasarkan kepemilikan; - Fungsi

Bangunan; - Tipologi Bentuk; - Tipe Denah; - Tipe Jendela; -

5. Pola Spasial Permukiman Desa Pantai Galesong- 1. Orientasi Pemukiman

2001

2. Pola sirkulasi pemukiman

(Kajian Terhadap Pola Spasial Permukiman Di

Desa Pantai Galesong Dan Pengaruh

3. Kepadatan hunian

4. Perubahan dan perkembangan bentuk hunian

5. Mata Pencaharian penghuninya

Asniawaty, et al

6. Tipologi dan Morfologi Arsitektur Suku Banjar - Desain (pola ruang, jumlah ruang, organisasi ruang, detail, di Kalimantan Selatan-2007

- Kesamaan yang menjadi ciri khas

- Pengaruh kebudayaan suku

- Pengaruh kepercayaan dan agama

Ira Mentayani, Dila Nadya Andini

- Tata Ruang

- Struktur dan Konstruksi

- Lokasi

- Ornamen/Ragam Hias

7. Transformation of Jalan Malioboro, Jogyakarta: The Morphology and Dynamics of a Javanese Street-2001

- Aspek fisik-spasial dari streetscape

- Aspek sosio-budaya tentang fungsi, makna, dan kegiatan yang sedang berlangsung di jalan

- Fungsi, makna, dan aktifitas

- Transformasi yang telah terjadi di masa lalu, saat ini prospek ke Wibisono depan

\section{Sumber: RD. Lestari}

\section{METODE PENELITIAN}

Kajian ini menggunakan metode deskriptif kualitatif dengan pendekatan rasionalistik dan tipo-morfologi agar dapat memahami fenomena serta pelaku di dalam setting natural (lingkup alamiah) (Denzin \& Lincoln, 1998: 1-3).

Pendekatan rasionalistik bertolak dari kerangka teoritik yang dibangun dari pemaknaan hasil penelitian terdahulu, teori-teori yang dikenal, buah fikiran para pakar, dan dikonstruksikan menjadi sesuatu yang mengandung sejumlah permasalahan yang perlu diteliti lebih lanjut.

Pendekatan tipo-morfologi genetik morfologis digunakan di dalam penelitian ini agar diperoleh deskripsi perkembangan atau perubahan (transformasi) bentuk ruang objek penelitian, sejak awal kehadirannya sampai bentuk terakhir (Muhadjir, 1992).

\section{HASIL DAN PEMBAHASAN}

\subsection{Elaborasi Teori dari Kajian Pustaka}


Diagram di bawah ini merangkum uraian dari teori-teori ruang dan mengelaborasikannya sehingga mengerucut menjadi unsur-unsur penting yang menjadi landasan teori dalam mengamati aspek fisik dan aspek non fisik pondok pesantren Salaf-tradisional yang telah dipaparkan pada bab Tinjauan Pustaka.

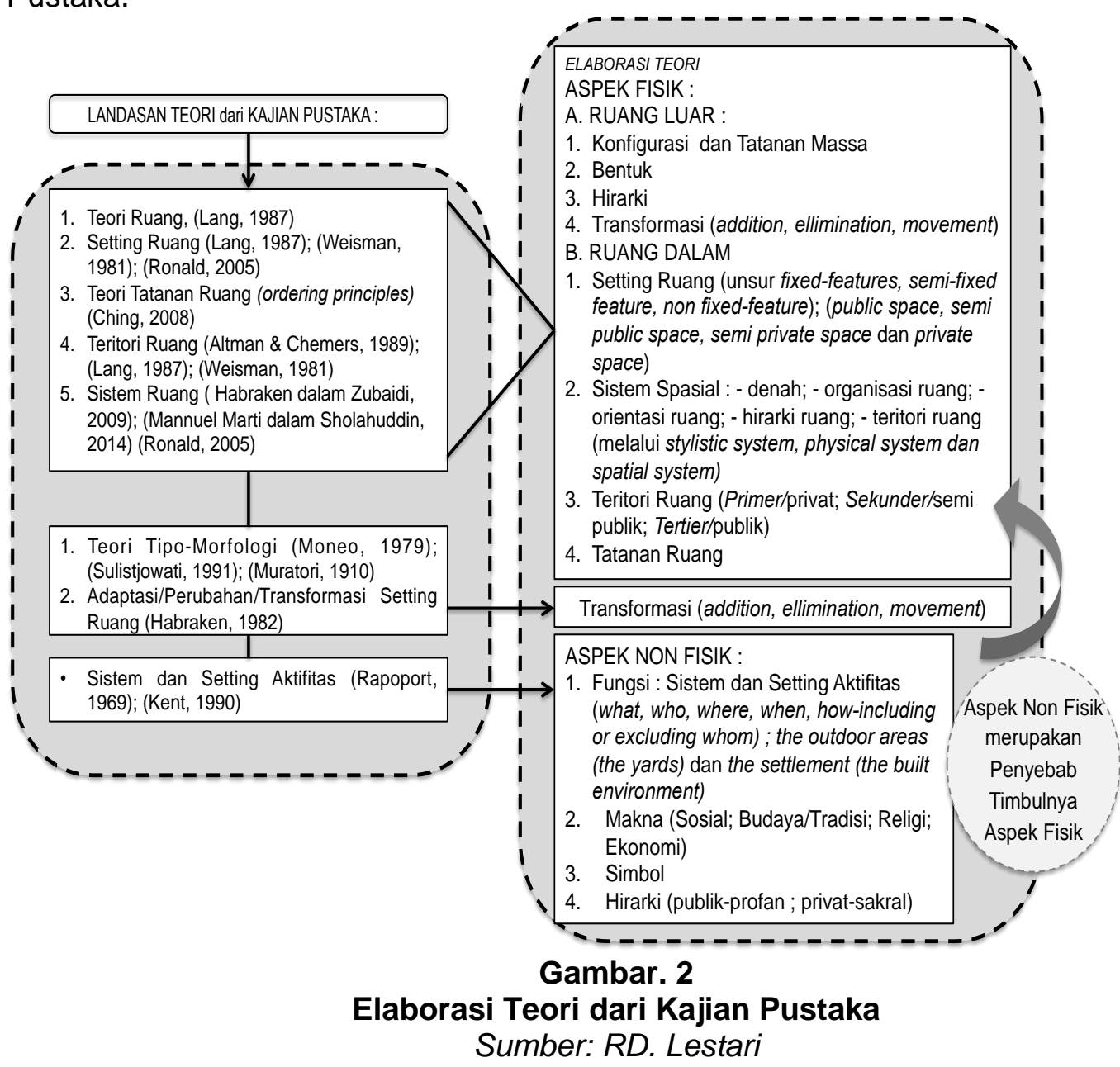

\subsection{Sintesa dari Objek Amatan Penelitian Terdahulu yang Terkait}

Gambar 3 di atas merupakan rangkuman dari objek-objek amatan pada tujuh (7) kajian yang sejenis yang telah dipaparkan pada bagian sebelumnya. Beberapa kajian memiliki perbedaan pada skala luas lingkungan amatan, sehingga sedikit berbeda dengan objek-objek amatan pada kajian ini yang lingkup kawasan penelitiannya lebih kecil, yaitu tapak kawasan dan ruangruang Pondok Pesantren. 


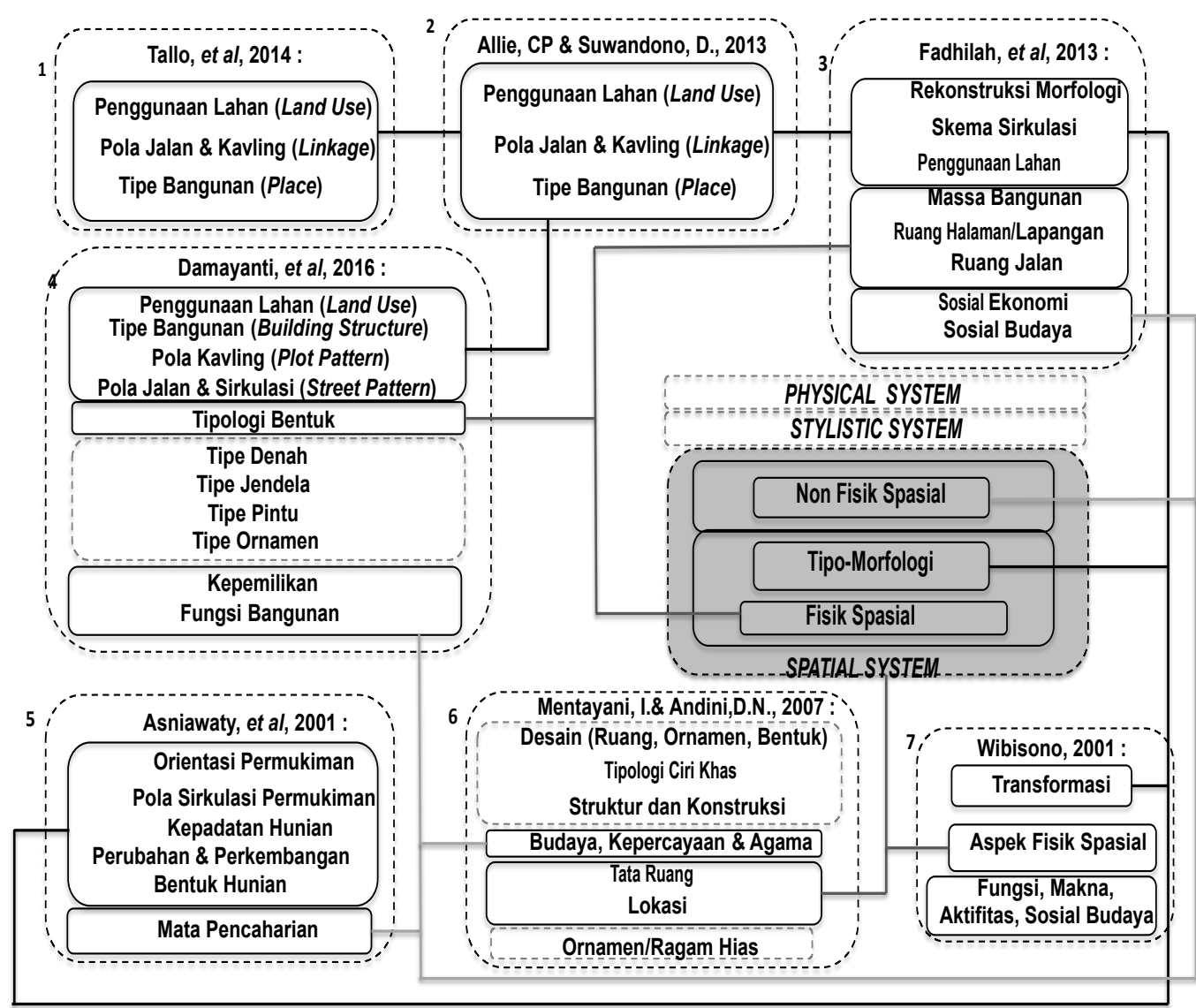

\section{Diagram Sintesa Objek-Objek Amatan \\ Sumber: RD. Lestari \\ Gambar. 3}

\subsection{Hasil Analisis Dan Pembahasan}

Melalui langkah-langkah di atas, hasil pembahasan dan analisis diuraikan dalam Tabel 2 di bawah ini. Tabel ini diharapkan dapat membantu tahapan penelitian karena telah difokuskan pada definisi operasional objek-objek amatan sehingga memudahkan dalam observasi di lapangan maupun wawancarara pada keynote speaker/ partisipan/ responden.

\section{Tabel 2.}

\section{Objek-Objek Amatan Langkah Penelitian}

\begin{tabular}{|c|c|c|c|c|c|}
\hline $\begin{array}{c}\text { Area } \\
\text { Penelitian }\end{array}$ & $\begin{array}{c}\text { Objek } \\
\text { Amatan }\end{array}$ & $\begin{array}{l}\text { Variabel } \\
\text { Amatan }\end{array}$ & $\begin{array}{c}\text { Kajian } \\
\text { Tipo-Morfologi Ruang }\end{array}$ & $\begin{array}{c}\text { Perolehan } \\
\text { Data }\end{array}$ & $\begin{array}{l}\text { Teknik } \\
\text { Analisis }\end{array}$ \\
\hline Ruang Luar & $\begin{array}{l}\text { ASPEK FISIK : } \\
\text { Organisasi Massa }\end{array}$ & - Bentuk Massa & $\begin{array}{l}\text { - Mengkaji bentuk massa } \\
\text { (simetris-asimetris terhadap } \\
\text { sumbu/axis). } \\
\text { - Mengkaji tinggi lantai } \\
\text { massa bangunan yang ada. }\end{array}$ & $\begin{array}{c}\text { Observasi Objek } \\
\text { Penelitian dan } \\
\text { Wawancara }\end{array}$ & \\
\hline
\end{tabular}




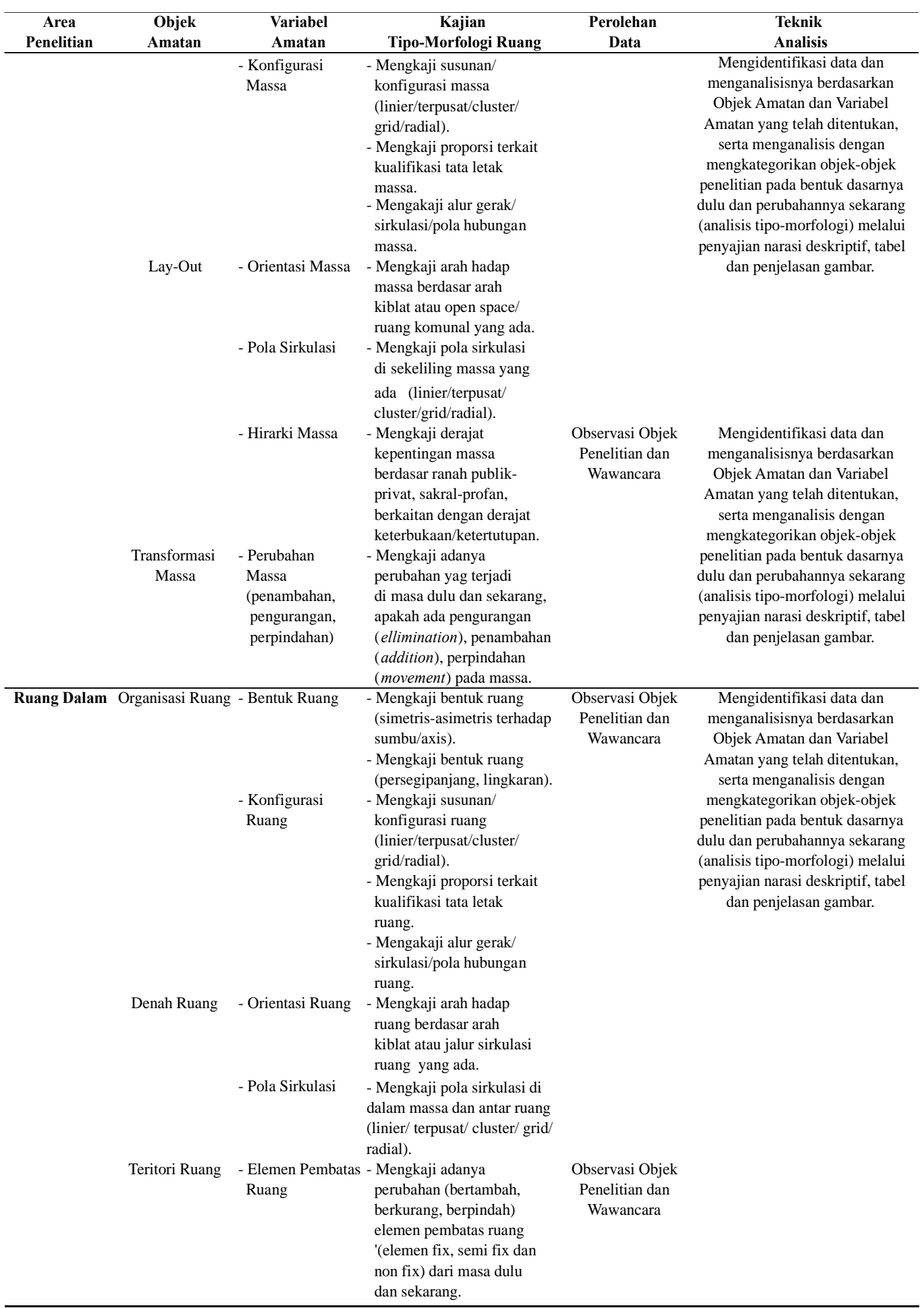




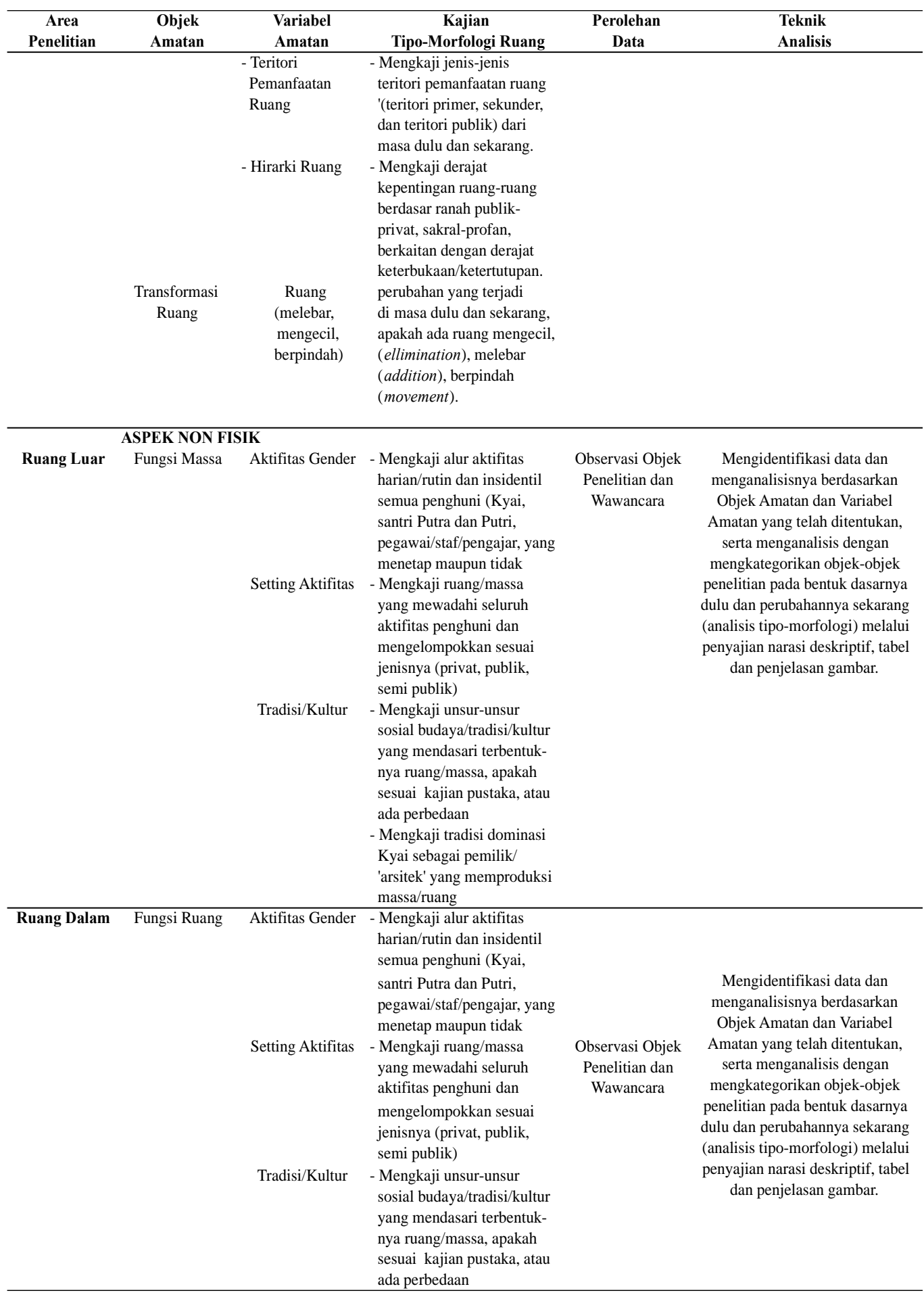

Sumber: RD. Lestari 


\section{KESIMPULAN}

Objek amatan pada Ruang Luar berupa, (1)Organisasi Massa, (2)Lay-Out dan (3)Tatanan Massa dengan variabel amatan (a)Bentuk Massa, (b)Konfigurasi Massa, (c)Orientasi Massa, (d)Pola Sirkulasi, (e)Hirarki Massa dan (f)Transformasi Massa. Objek Amatan pada Ruang Dalam yaitu, (1)Organisasi Ruang, (2)Denah Ruang, (3)Teritori Ruang dan (4)Tatanan Ruang dengan variabel amatan (a)Bentuk Ruang, (b)Konfigurasi Ruang, (c)Orientasi Ruang, (d)Sirkulasi Ruang, (e)Elemen Pembatas Ruang, (f)Teritori Pemanfaatan Ruang, (g)Hirarki Ruang dan (h)Transformasi Ruang.

Melalui objek-objek amatan di atas akan dapat ditemukan tipo-morfologi Ruang suatu objek penelitian (dalam hal ini Pondok Pesantren SalafTradisional). Objek ini masih sangat jarang dikaji, terutama dari sudut pandang Arsitektural. Perlu diperbanyak lagi kajian-kajian sejenis agar nilai-nilai Islam yang luhur dalam tradisinya mampu disebarluaskan menjadi perisai terhadap penetrasi budaya dan kultur barat yang tidak sesuai dengan nilai-nilai ketimuran maupun nilai-nilai Islam.

\section{DAFTAR PUSTAKA}

1. Aguspriyanti, C.,D. \& Pujiono, M., S., 2012. Ambiguous Space : Peleburan Ruang Luar dan Ruang Dalam Sebagai Bentuk Penyamaran Makna Ruang. Jurnal Sains Dan Seni Pomits. I(1): 1-4. $\quad$ Surabaya: Jurusan Arsitektur, Fakultas Teknik Sipil (ITS).

2. Ali, Mukti. 1987. Beberapa Persoalan Agama Dewasa Ini. Jakarta: Rajawali Press.

3. Altman, I. \& Chemers M.M. 1989. Culture \& Environment. New York: Cambridge University Press.

4. Ashihara, Y. 1983. Exterior Design in Architecture. Terjemahan S. Gunadi. Surabaya: Surya Offset.

5. Ching, F., D.K., 2008. Architecture : Form, Space and Order. New York : Van Nostrand Reinhold.

6. Ciptadi. W. 2014. Perubahan Pola Organisasi, Hirarki dan Orientasi Ruang Rumah Tinggal Tradisional Melayu Pontianak Tipe Potong Limas di Sekitar Komplek Kraton Kadriyah Pontianak. Jurnal Vokasi. X(2): 89-97.

7. Denzin, Norman K. \& Lincoln, Yvonna S. 1998. The Landscape of Qualitative Research : Theories and Issues. Copyright by Sage Publications.

8. Dhofier, Zamakhsyari. 2011. Tradisi Pesantren: Studi Pandangan Hidup Kiai dan Visinya Mengenai isepi:Masa Depan Indonesia. Jakarta: LP3ES. IX: 41.

9. Habraken, N.J. 1982. Transformation of The Site. Massachusetts: MITT.

10. Ibrahim, R., 2014. Eksistensi Pesantren Salaf di Tengah Arus Pendidikan Modern: Studi Multisitus pada Beberapa Pesantren Salaf di Jawa Tengah. Jurnal "Analisa”. XXI(02): 253-263. 
11. Kent, Susan. 1990. Domestic Architecture of the Use of Space: An Interdisciplinary Cross-Cultural Study. New York, Cambridge: Cambridge University Press.

12. Lang, J. 1987. Creating Architectural Theory. New York: Von Nostrand Reinhold.

13. Moneo, R., 1979. On Typology. Journal Oppositions. XIII: 23-45.

14. Moudon, Anne Vernez. 1997. Urban Morphology as an Emerging Interdisciplinary Field. Journal of Urban Morphology. I: 3-10. Seattle, WA 98195, USA: College of Architecture and Urban Planning, University of Washington.

15. Muhadjir, N., 1992. Metode Penelitian Kualitatif. Tesis. Tidak dipublikasikan. Yogyakarta: Universitas Gadjah Mada.

16. Nata, Abuddin. 2012. Kapita Selekta Pendidikan Islam, Isu-isu Kontemporer tentang Pendidikan Islam. Jakarta: Rajagrafindo Perkasa.

17. Oliver, Paul, 1997. Encyclopedia of Vernacular Architecture of the World. Cambridge University Press.

18. Rapoport, A. 1969. House Form and Culture. Published by: Prentice-Hall, Inc. Englewood Cliffs, e-ispein 07632 US.

19. Rofi', Sofyan, 2016. Sejarah Pendidikan Islam di Indonesia. Deeppublish.

20. Ronald, A. 2005. Nilai-nilai Arsitektur Rumah Tradisional Jawa. Yogyakarta: Universitas Gajah Mada Press.

21. Sholahuddin, M., 2014. Urbanisasi Spasial dan Pengaruhnya pada Perubahan Struktur Spasial pada Rumah Tinggal (Studi Kasus di Sewon, Bantul, Yogyakarta). Jurnal of Urban Society's Arts. I(2): 14916. Weisman, J. (1981). Evaluating Architectural Legibility: Way-finding and the Built Environment. Environment and Behavior. XIII(2): 18920.

22. Zevi, Bruno, 1957. Architecture as Space. How to Look at Architecture. New York: Horizon Press, 21.

23. Zubaidi, Fuad. 2009. Arsitektur Kaili sebagai Proses dan Produk Vernakular. Jurnal Ruang. I(1): 62-75. Fakultas Teknik Jurusan Arsitektur Universitas Tadulako, Palu. 